18

\title{
Полевой эффект в графене при интерфейсном контакте с водными растворами уксусной кислоты и гидроксида калия
}

\author{
(C) А.В. Бутко ${ }^{1}$, В.Ю. Бутко ${ }^{1,2, \uparrow}$, С.П. Лебедев ${ }^{1,3}$, А.А. Лебедев ${ }^{1}$, Ю.А. Кумзеров ${ }^{1}$ \\ ${ }^{1}$ Физико-технический институт им. А.Ф. Иофрее РАН, \\ Санкт-Петербург, Россия \\ ${ }^{2}$ Санкт-Петербургский академический университет, \\ Санкт-Петербург, Россия \\ ${ }^{3}$ Санкт-Петербургский национальный исследовательский университет \\ информационных технологий, механики и оптики, \\ Санкт-Петербург, Россия \\ ๑E-mail: vladimirybutko@gmail.com
}

(Поступила в Редакцию 28 марта 2017 г.)

Для создания новых перспективных химических сенсоров большое значение имеет исследование влияния на транзисторные характеристики графена его интерфейса с водными растворами кислот и щелочей. Созданы и исследованы транзисторные структуры на основе графена, выращенного путем термического разложения карбида кремния. Для интерфейса графена с водными растворами уксусной кислоты и гидроксида калия в транзисторной геометрии при изменении напряжения между затвором и истоком обнаружен полевой эффект, соответствующий дырочному типу носителей заряда в графене. Установлено, что увеличение концентрации молекулярных ионов в данных растворах приводит к усилению зависимости сопротивления транзистора от напряжения на затворе.

Работа частично поддержана РФФИ (проект № 14-02-01212) и РНФ (проект № 15-12-00027).

DOI: 10.21883/FTT.2017.10.44981.097

\section{1. Введение}

Транзисторные структуры на основе графена перспективны для создания нового поколения химических и биологических сенсоров. Например, в работе [1] заявлено создание $\mathrm{pH}$-транзисторного сенсора на основе четырехслойного графена, находящегося вблизи точки Дирака, полученного методом термического разложения карбида кремния, в котором исследуемая жидкость исполняет роль изолятора между поверхностью графена и затвором. Полевой транзистор был создан с помощью фотолитографии, контакты находились на расстоянии $0.5 \mathrm{~mm}$. Исследователи регистрировали зависимость сопротивления графена от напряжения на затворе при различных значениях $\mathrm{pH}$. При изменении $\mathrm{pH}$ раствора наблюдалось смещение точки Дирака (при увеличении pH раствора точка Дирака сдвигается в положительную сторону). Ряд результатов данной работы подвергался сомнению в других публикациях [2,3]. Таким образом, дальнейшее исследование транзисторных характеристик графена в области при его интерфейса с водными растворами кислот и щелочей имеет практическое значение. В настоящей работе проводится исследование графена, полученного с помощью термического разложения карбида кремния, который без дополнительной термической обработки находится вдали от точки Дирака.

\section{2. Экспериментальные методы}

Графен, получаемый с помощью термического разложения карбида кремния, является одним из наиболее перспективных материалов для практических приложений благодаря возможности использования высококачественных образцов большой площади. В настоящей работе для роста графена подложка карбида кремния нагревалась до $\sim 1400^{\circ} \mathrm{C}$ в условиях вакуума $\sim 10^{-6}$ Torr в течение 10-20 min. Диагностика и оценка толщины (2-4 монослоя) исследуемых образцов графена была выполнена в работе [4] с использованием метода рамановской спектроскопии. Для проведения электрических измерений в настоящей работе контакты к графену изготавливались с использованием серебряной пасты и контактных золотых проволок. Типичное расстояние между контактами было порядка $1 \mathrm{~mm}$. Контактные площадки и барьерный изолятор в исследуемых устройствах расположены поверх изучаемого полупроводника (графена). Такая геометрия транзисторных структур схожа с геометрией исследованных нами ранее транзисторов на основе монокристаллов органических полупроводников [5,6]. Исследуемые в настоящей работе транзисторные структуры (рис. 1) аналогичны структурам графена с водным барьерным изолятором, описанным нами в [4]. В отличие от упомянутой публикации в настоящей работе в качестве барьерных изоляторов используются водные растворы кислот (уксусная кис- 


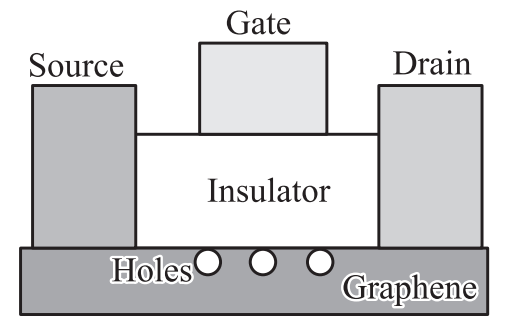

Рис. 1. Схема полевого транзистора.

лота) и щелочей (гидроксид калия) разной молярной концентрации. В изучаемых структурах потенциал на затворе направляет ионы в исследуемой жидкости к интерфейсу с графеном, что приводит к изменению электрических свойств графена. Серебряные контактные площадки изолировались от водных растворов при помощи клея GE Varnish. Измерения были автоматизированы и проводились в реальном времени с помощью программы, написанной нами на языке Lab VIEW. Измерения осуществлялись вольтметрами AKIP B7-78/1.

\section{3. Результаты}

Из рис. 2 видно, что при изменении напряжения между затвором и истоком наблюдается изменение сопротивления графена (полевой эффект). Рис. 2 демонстрирует также, что полученная зависимость от напряжения затвора различается для водных растворов уксусной кислоты и гидроксида калия на одном образце графена. Для водного раствора уксусной кислоты наблюдается ускоренное падение сопротивления полевого транзистора при достижении определенного порогового

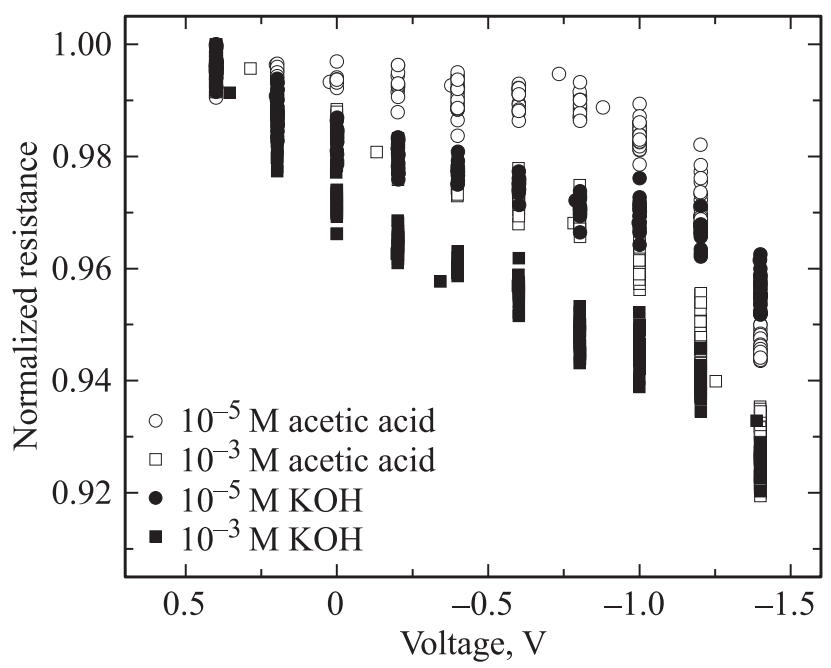

Pис. 2. Зависимость от напряжения между затвором и истоком сопротивления графена при его контакте с водным раствором уксусной кислоты и с водным раствором гидроксида калия на одном и том же образце. напряжения на затворе, тогда как в области интерфейса графена со щелочным раствором гидроксида калия наблюдается практически линейная зависимость сопротивления полевого транзистора от напряжения между затвором и истоком. Полевой эффект в этих структурах связан с возможностью управления напряжением с помощью величины электрического заряда на интерфейсе графена с водным раствором. Обнаруженный полевой эффект соответствует дырочному типу носителей заряда в графене в отличие от электронного типа носителей заряда, характерного для монослойного графена, выращенного схожим методом [7]. Обнаруженное различие типа носителей заряда, возможно, частично обусловлено

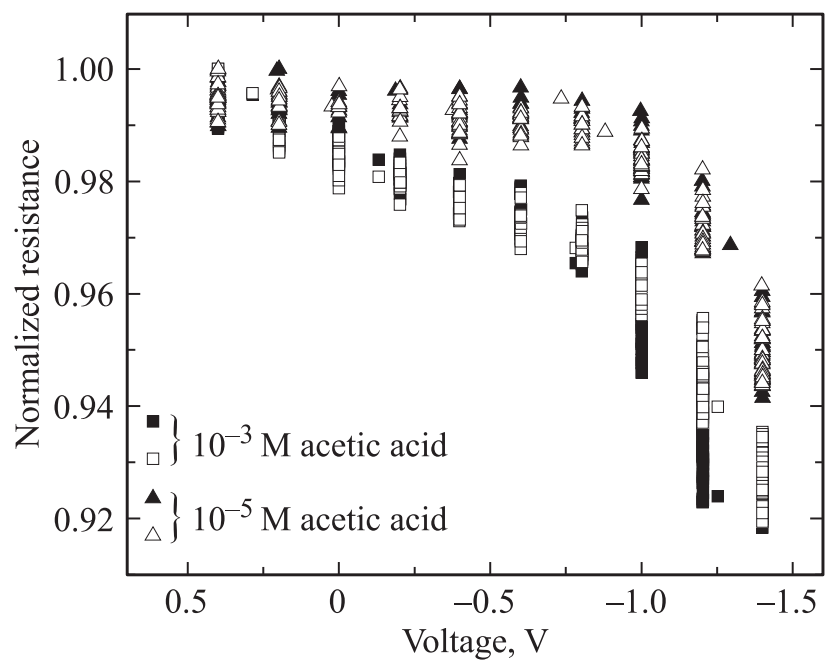

Рис. 3. Зависимость от напряжения между затвором и истоком сопротивления графена при его контакте с водным раствором уксусной кислоты для различных измерений при двух молярных концентрациях на одном образце.

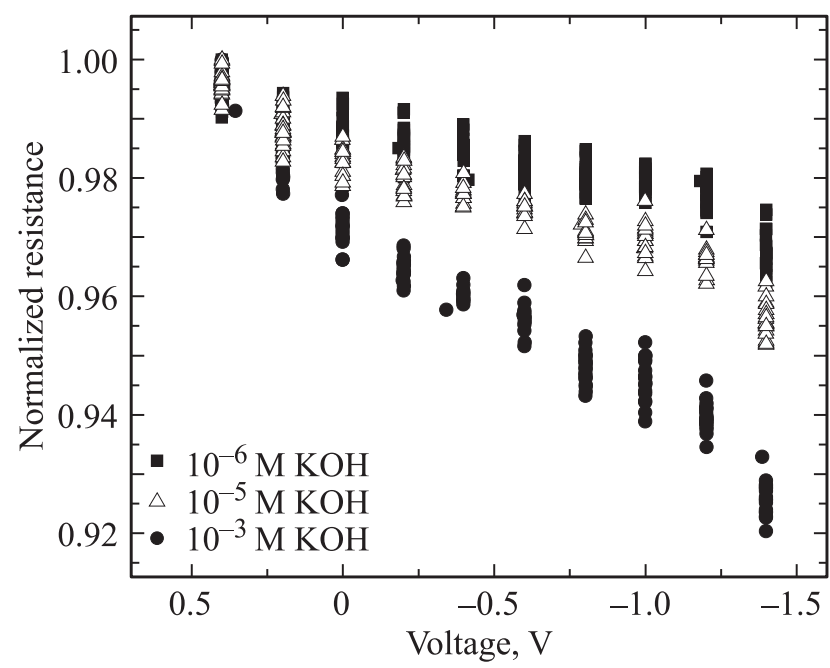

Рис. 4. Зависимость от напряжения между затвором и истоком сопротивления графена при его контакте с водным раствором гидроксида калия для трех молярных концентраций на одном образце. 
дырочным допированием графена при его взаимодействии с молекулами водных растворов [8]. Из рис. 3 и 4 видно, что увеличение концентрации молекулярных ионов в данных растворах приводит к усилению зависимости сопротивления транзистора от напряжения между затвором и истоком.

\section{4. Заключение}

Обнаружен полевой эффект, знак которого демонстрирует, что дырки являются основным типом носителей заряда в исследуемом графене. Полученные результаты свидетельствуют о потенциальной возможности создания сенсоров на основе графена, которые позволяют определеть молярную концентрацию для исследованных типов водных растворов кислот и щелочей.

Авторы благодарны В.Ю. Давыдову, А.Н. Смирнову, А.А. Сысоевой и А.В. Фокину за помощь.

\section{Список литературы}

[1] P.K. Ang, W. Chen, A.T.S. Wee, K.P. Loh. J. Am. Chem. Soc. 130, 14392 (2008).

[2] W. Fu, C. Nef, O. Knopfmacher, A. Tarasov, M. Weiss, M. Calame, C. Schonenberger. Nano Lett. 11, 3597 (2011).

[3] M.H. Lee, B.J. Kim, K.H. Lee, I.S. Shin, W. Huh, J.H. Cho, M.S. Kang. Nanoscale 7, 7540 (2015).

[4] А.В. Бутко, В.Ю. Бутко, С.П. Лебедев, А.Н. Смирнов, В.Ю. Давыдов, А.А. Лебедев, Ю.А. Кумзеров. ФТТ 58, 1432 (2016).

[5] V.Y. Butko, X. Chi, D.V. Lang, A.P. Ramirez. Appl. Phys. Lett. 83, 4773 (2003).

[6] V.Y. Butko, X. Chi, A.P. Ramirez. Solid State Commun. 128, 431 (2003).

[7] L.H. Hess, M.V. Hauf, M. Seifert, F. Speck, T. Seyller, M. Stutzmann, I.D. Sharp, J.A. Garrido. Appl. Phys. Lett. 99, 033503 (2011).

[8] T. Feng, D. Xie, G. Li, J. Xu, H. Zhao, T. Ren, H. Zhu. Carbon 78, 250 (2014). 